\title{
Association of Tri-Ponderal Mass Index vs Body Mass Index With Mid-Upper Arm Circumference Among Adolescent Girls
}

\section{Shreyasi Roy and Jaydip Sen}

Department of Anthropology, University of North Bengal, Raja Rammohunpur, Darjeeling, West Bengal, India

\section{Correspondence: \\ Shreyasi Roy \\ Department of Anthropology, \\ University of North Bengal, \\ Raja Rammohunpur, \\ Darjeeling-734 013, \\ West Bengal, India \\ E-mail: shreyasiroy93@gmail.com}

DOI: $10.3126 /$ jnps.v41i1.29573

Submitted on: $2020-06-22$

Accepted on: 2021-02-16

Acknowledgements: None

Funding: Nil

Conflict of Interest: None declared

Permission from IRB: Yes

To cite this article: Roy S, Sen J. Association of Tri-Ponderal Mass Index vs Body Mass Index With Mid-Upper Arm Circumference Among Adolescent Girls. J Nepal Paediatr Soc. 2021;41(1): 11-16.

\begin{abstract}
Introduction: Since 2017, number of studies involving nutritional status of adolescents using a novel parameter named tri-ponderal mass index (TMI) is soaring high. The concept of TMI was formulated to substitute body mass index (BMI) in case of adolescent population. The present study aims to find TMI values of school-going adolescent girls (aged 10 to 19 years). It also aims to compare the association of TMI and BMI with mid-upper arm circumference (MUAC) of the subjects.
\end{abstract}

Methods: Height, weight and MUAC were measured using standard procedures. The BMI and TMI were accordingly calculated. The data obtained was tabulated to elucidate age-wise descriptive statistics. Quadratic polynomial regression was employed to yield a general conclusion regarding association of TMI and BMI with MUAC of the subjects. Receiver operating characteristic (ROC) curve was plotted to check which of the two indices, BMI or TMI, has better ability to predict higher MUAC of the subjects.

Results: The ROC-area under curve (AUC) was 0.867 and 0.955 for TMI and BMI respectively.

Conclusion: BMI has better association with MUAC. In comparison to TMI, BMI has superior ability in predicting higher MUAC of the subjects.

Keywords: Adolescent girls; BMI; MUAC; Tri - ponderal 


\section{INTRODUCTION}

Body Mass Index (BMI) was originally developed by Lambert Adolphe Jacque Quetelet in the year 1832 and was named as Quetelet Index \{later renamed as Body Mass Index in 1972 by Ancel Keys (1904-2004)\}. ${ }^{1}$ It has been formulated based on the finding that normal body weight in kilograms was proportional to the square of the height in meters. ${ }^{2}$ This was formulated for adults as Quetelet noted that the body mass relationship to height in normal young adults was least affected by height when the ratio of weight to height squared was used rather than other equations developed at that period. ${ }^{3}$ However, this was supposed to be ruled out in case of adolescents. Quetelet ${ }^{4}$ in his book 'A Treatise on Man and the Development of His Faculties' assumed that "during development, the squares of the weight at different ages are as the fifth powers of the height" i.e., mass ${ }^{2}$ increases with height ${ }^{5}$. In the later years, several researches regarding weight for height indices came up which further brought several studies based on the serial change in the exponent ' $p$ ' of weight/heightp (also called Benn's index) through several stages of human growth. Dugdale proposed weight/height ${ }^{2.42}$ as age independent nutrition indices for children above five years. ${ }^{5}$ Cole showed that ' $p$ ' rises from age five to 12 years by differentiating the National Center for Health Statistics (NCHS) median standard weight/height curves plotted against age. ${ }^{6}$ More precisely, Cole also found that the optimal value of ' $p$ ' was two in pre-school children, but it increased gradually to three at age 11 and fell back to two after puberty. ${ }^{7} \mathrm{He}$ further concluded that BMI is appropriate for preschool children and adults. However, early in puberty it tends to assess tall or physically advanced children as being overweight. ${ }^{7}$

Despite being unfit for assessing nutritional status, BMI has been extensively used as a proxy measure to determine nutritional status of adolescent individuals. ${ }^{8-10}$ It was concluded that BMI performs as good as standardised BMI, Fat-Free Mass Index (FFMI), Fat Mass Index (FMI), TMI, Waist-toHeight ratio (WtHR) and Body Mass Fat Index (BMFI) and therefore must be preferred in metabolic syndrome and obese children and adolescents. ${ }^{11}$ Another reason for preferring BMI to other adiposity indices was ease of calculation compared to other indices. Later, standardised BMI and BMI-for-age percentile charts were developed to assess nutritional status of adolescents. A novel parameter named tri-ponderal mass index (TMI) has been extensively used in several recent studies for assessing nutritional status of adolescent individuals. TMI is defined as weight divided by height cubed. It bears the formula: TMI = weight in kilogram / height in meter ${ }^{3}$. The unit of TMI is $\mathrm{kg} /$ $\mathrm{m}^{3}$. The prefix 'tri' is a reminder that height is raised to the third power which makes it different from 'ponderal index' where height is raised only to the first power.

Although there exists an emerging body of evidences involving TMI of adolescents, there is a dearth of widely-accepted cut-offs. Several studies mentioned above yielded a strong conclusion that TMI estimates body fat levels accurately. However, there are few studies claiming association of TMI and mid-upper arm circumference (MUAC) of adolescent populations. With the above issues in mind, the present study aimed to estimate TMI values of adolescent girls and to compare the association of TMI and BMI with MUAC. The study also aimed to find which of these indices, TMI or BMI, has the ability to predict higher MUAC among the subjects.

\section{METHODS}

The present cross-sectional study was conducted among 469 school-going adolescent girls (aged 10 to 19 years) belonging to the Bengalee Hindu Caste Population (BHCP) and residing in Siliguri town, West Bengal, India. Ethnically, BHCP is a Bengalispeaking endogamous caste group of West Bengal and faithful to Hinduism. They are probably a blend of Dravidian and Mongoloid ethnic groups with a strain of Indo-Aryan blood among the higher caste groups. ${ }^{12}$ This study was conducted on a government secondary school situated at the heart of Siliguri town. The minimum number of sample size required for reliable estimate and assessment of nutritional status was calculated utilising the standard sample size estimation procedure of Lwanga and Lemeshow. ${ }^{13}$ The minimum sample size for this study was estimated to be 384 individuals. The final sample size was much higher 
than this estimated size. A stratified sampling method was used to select the girls in the present study. A total of 525 apparently healthy adolescent girls belonging to the BHCP were selected. Ten girls declined to participate in the study and 46 girls were excluded because their ages were not within the age group selected for the present study. This yielded a final sample size of 469 individuals. The study was conducted in accordance with the ethical guidelines for human experiments, as laid down by the Helsinki Declaration of 2000. ${ }^{14}$ Permission was taken from the Institutional Research Board of the University.

Anthropometric measurements of height, weight and MUAC were collected using standard procedures. ${ }^{15}$ Measurements were taken to the nearest $0.1 \mathrm{~cm}$ for height and $0.5 \mathrm{~kg}$ for weight. BMI and TMI were subsequently calculated from weight (in $\mathrm{kg}$ ) and height (in metres). To check the consistency of the data, accuracy index named Technical Error of Measurement (TEM) was calculated. ${ }^{16}$ For the calculation of intra-observer TEM, height, weight and MUAC were recorded from $50 \mathrm{BHCP}$ adolescent girls other than those selected for the study. The measurements were recorded thrice on each individual by the author. It was calculated by the formula: TEM $=\sqrt{ }\left(\Sigma \mathrm{D}^{2} /\right.$ $2 \mathrm{~N}$ ), where $\mathrm{D}=$ difference between the measurements and $\mathrm{N}=$ number of individuals. The coefficient of reliability (R') which estimates the proportion of variance in a measured population that is free from measurement error was subsequently calculated by the equation: $R^{\prime}=\{1-$ $\left.(\mathrm{TEM})^{2} / \mathrm{SD}^{2}\right\}$, where SD = standard deviation of the measurements. Very high values of R' $(>0.980)$ were obtained for the intra-observer TEM analysis. All the values of $R^{\prime}$ were appreciably higher than the accepted cut-off value of 0.95 as suggested by Ulijaszek and Kerr. ${ }^{17}$ Hence, the anthropometric measurements recorded by SR were considered to be reliable and reproducible and the TEM values were not incorporated for further statistical consideration. The data recorded in the present study was statistically analysed with the aid of Statistical Package for Social Science (IBM SPSS Statistics, version 23.0, SPSS Inc., Chicago, IL) using relevant statistical constants and relevant statistical tests. Age-wise descriptive statistics of all the variables were framed. The one-way analysis of variance (ANOVA) was performed to check significant statistical differences in age-wise mean TMI, BMI and MUAC of the subjects.

Quadratic polynomial regression was performed to compare the association of TMI and BMI with MUAC. This was preferred to linear regression which gave lower values of $\mathrm{R}$ and $\mathrm{R}^{2}$. For receiver operating characteristics (ROC) curve analysis, a MUAC cut-off was required to classify the subjects with higher and lower MUAC values. However, owing to absence of widely accepted MUAC cutoffs among adolescent populations, we preferred to choose a particular MUAC cut-off value of $22 \mathrm{~cm}$. The cut-off was used in a study ${ }^{18}$ to compare the haemoglobin values of the non-school going adolescent girls (11-19 years) of Odisha. The study reported significantly lower mean haemoglobin levels in those with low MUAC $(<22 \mathrm{~cm})$ than those with $M U A C \geq 22 \mathrm{~cm}$.

\section{RESULTS}

Age-specific descriptive statistics of $\mathrm{BHCP}$ adolescent girls are displayed in Table 1. Mean TMI, BMI and MUAC of the subjects were $13.64 \pm$ $1.87 \mathrm{~kg} / \mathrm{m}^{3}, 19.82 \pm 2.93 \mathrm{~kg} / \mathrm{m}^{2}$ and $21.58 \pm 3.13$ $\mathrm{cm}$ respectively. TMI values tend to increase with age except at age 11, 14 and 15 years. BMI values of the subjects tend to increase with age. MUAC

Table 1. Age-specific descriptive statistics (mean \pm standard deviation) of the subjects

\begin{tabular}{lrccc}
$\begin{array}{l}\text { Age } \\
(\text { years })\end{array}$ & No & $\begin{array}{c}\text { TMI } \\
\left(\mathbf{k g} / \mathbf{m}^{3}\right)\end{array}$ & $\begin{array}{c}\text { BMI } \\
\left(\mathbf{k g} / \mathbf{m}^{2}\right)\end{array}$ & $\begin{array}{c}\text { MUAC } \\
(\mathbf{c m})\end{array}$ \\
\hline 10 & 50 & $11.15 \pm 1.71$ & $14.39 \pm 2.53$ & $18.14 \pm 2.50$ \\
11 & 47 & $10.96 \pm 1.76$ & $14.94 \pm 2.59$ & $19.06 \pm 2.58$ \\
12 & 45 & $11.31 \pm 2.24$ & $16.18 \pm 3.15$ & $20.27 \pm 2.95$ \\
13 & 58 & $11.98 \pm 1.69$ & $17.43 \pm 2.44$ & $21.18 \pm 2.64$ \\
14 & 39 & $11.64 \pm 1.49$ & $17.49 \pm 2.37$ & $21.93 \pm 2.70$ \\
15 & 58 & $11.80 \pm 1.50$ & $17.75 \pm 2.34$ & $22.25 \pm 2.46$ \\
16 & 47 & $12.31 \pm 1.49$ & $18.53 \pm 2.19$ & $23.33 \pm 2.09$ \\
17 & 52 & $12.75 \pm 2.21$ & $18.98 \pm 3.06$ & $23.03 \pm 2.50$ \\
18 & 52 & $12.97 \pm 1.66$ & $19.59 \pm 2.48$ & $24.00 \pm 2.62$ \\
19 & 21 & $13.32 \pm 1.65$ & $20.04 \pm 2.52$ & $23.43 \pm 1.74$ \\
Total & 469 & $13.64 \pm 1.87$ & $19.82 \pm 2.93$ & $21.58 \pm 3.13$
\end{tabular}


A

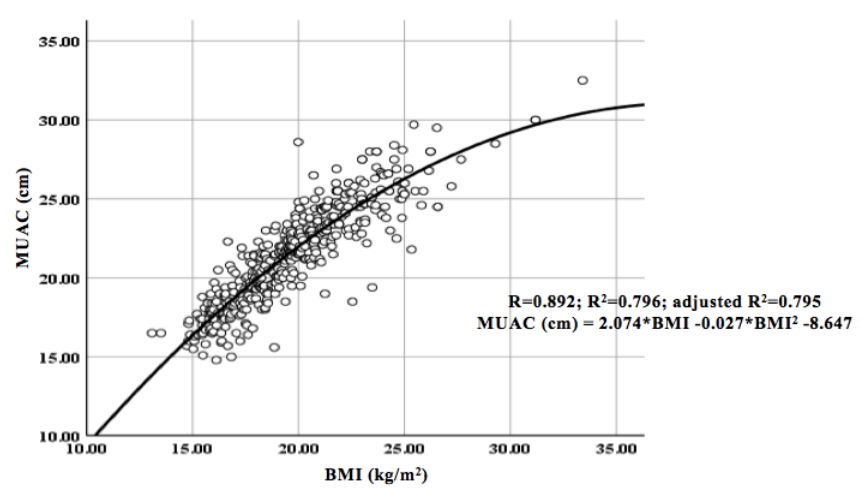

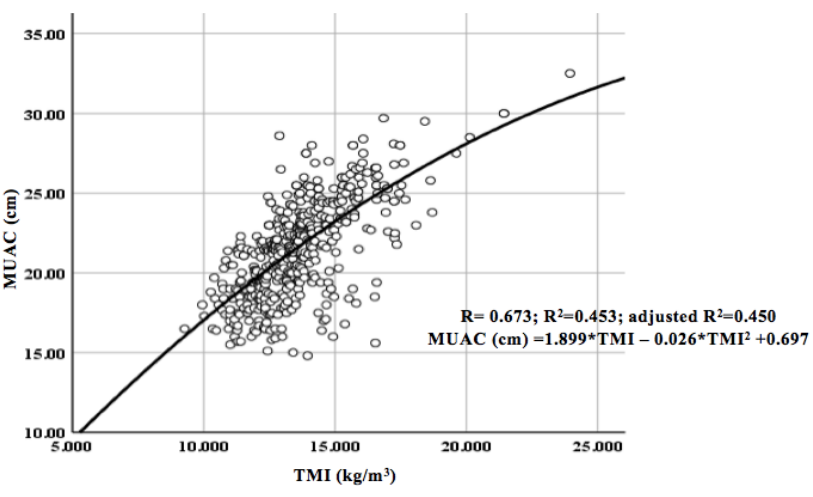

Figure 1. Quadratic polynomial regressions for (A) BMI and (B) TMI as predictors of MUAC

values tend to increase with age except at age 17 and 19 years. The ANOVA analysis showed statistical significant differences in age-wise mean TMI $($ F-value $=8.262)$, BMI $($ F-value $=27.354)$ and MUAC $(\mathrm{F}-$ value $=37.223)(\mathrm{p}<0.001)$.

Quadratic polynomial regression showed that BMI has better association with MUAC $(\mathrm{R}=$ $0.892)$ in comparison to TMI $(\mathrm{R}=0.673)$. The association could be better understood from Fig 1. The receiver operating characteristics (ROC) analysis yields area under curve (AUC) values of 0.867 for TMI and 0.955 for BMI (Fig. 2).

\section{DISCUSSION}

According to our literature search, there is almost no research paper involving TMI of adolescents in
India. The present study has made an attempt to estimate TMI values of adolescent girls, though the sample size is small. The overall mean TMI values among girls estimated in the present study was $13.64 \pm 1.87 \mathrm{~kg} / \mathrm{m}^{3}$. The value is quite less compared to another study ${ }^{19}$ and is higher compared to some other studies. ${ }^{20-22}$ The present study found that TMI values tend to increase with age. This finding corroborates with another study. ${ }^{21}$ However, several studies claimed that TMI values showed a decreasing trend with increase in age (except at few age points). ${ }^{23,24}$

Our literature search has not found any study seeking for association between TMI and MUAC of adolescent girls. However, there exist several studies that attempted to find the association between BMI and MUAC of adolescent girls (Table

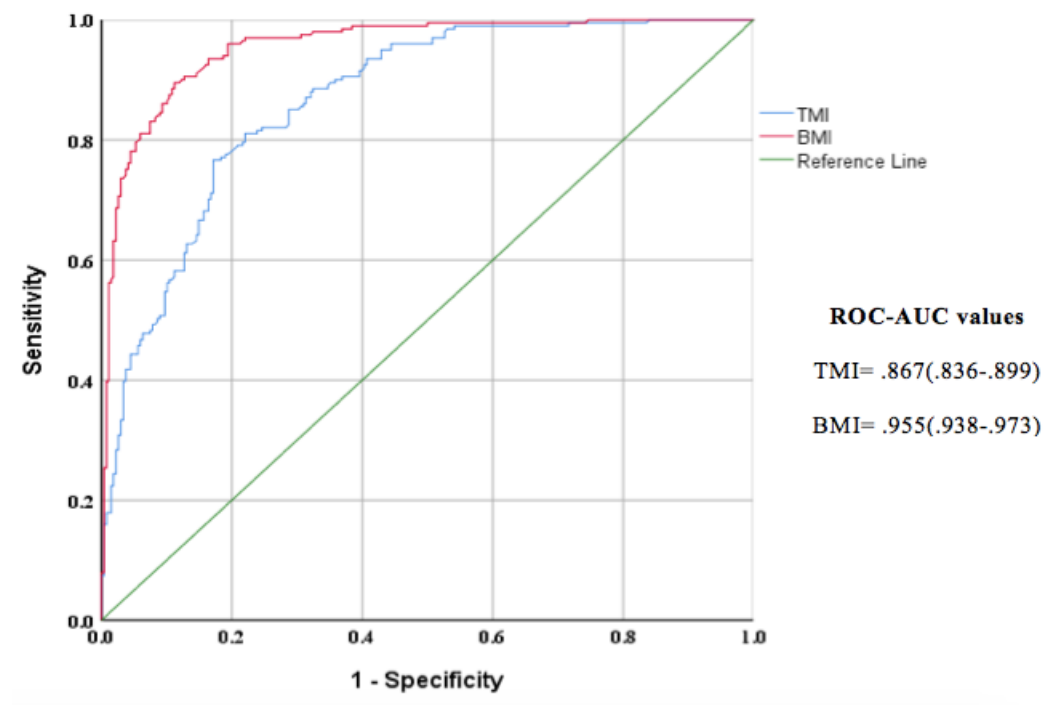

Figure 2. ROC curve analysis showing ability of TMI and BMI to predict higher MUAC among adolescent girls 
Table 2. Correlation between BMI and MUAC among various studies conducted on adolescent girls

\begin{tabular}{|c|c|c|c|c|}
\hline Studies & Region & Subjects & $\begin{array}{l}\text { Age range } \\
\text { (years) }\end{array}$ & Correlation \\
\hline Jeyakumar et al. ${ }^{25}$ & $\begin{array}{l}\text { Maharashtra, } \\
\text { India }\end{array}$ & $\begin{array}{l}\text { Adolescent unmarried } \\
\text { girls residing in urban slums }\end{array}$ & $16-18$ & $0.593(\mathrm{p}=.000)$ \\
\hline Sethi et al. ${ }^{26}$ & $\begin{array}{l}\text { Chhattisgarh } \\
\text { and Odisha, India }\end{array}$ & $\begin{array}{l}\text { Adolescent girls } \\
\text { from four } \\
\text { tribal blocks }\end{array}$ & $10-19$ & $\begin{array}{l}0.78 \text { (overall) } \\
0.82 \text { (Chhattisgarh) } \\
0.77 \text { (Odisha) } \\
(\mathrm{P}=0.001)\end{array}$ \\
\hline Lillie et al. ${ }^{27}$ & $\begin{array}{l}\text { Pwani Region } \\
\text { and Dar es Salaam } \\
\text { Region, Tanzania }\end{array}$ & $\begin{array}{l}\text { Adolescents attending } \\
\text { last year of primary school }\end{array}$ & - & $\begin{array}{l}0.846 \\
(p<0.001)\end{array}$ \\
\hline Present study & $\begin{array}{l}\text { Siliguri, } \\
\text { West Bengal, India }\end{array}$ & $\begin{array}{l}\text { Adolescent BHCP } \\
\text { school-going girls }\end{array}$ & $10-19$ & $0.892(\mathrm{p}=0.000)$ \\
\hline
\end{tabular}

2). The findings proved that there always existed a strong positive correlation between the variables. In the comparison between the ROC curves for the indices, BMI was found to present a significantly higher AUC for indicating higher MUAC among the subjects. In particular, the AUC for BMI was 0.955 (95\% CI: 0.938 - 0.973; S.E.: 0.01; p < $0.001)$ and AUC for TMI was 0.867 (95\% CI: . 836-.899; S.E.: 0.01; $p<0.001)$. AUC values above 0.85 depicts excellent diagnostic test. This proves that both TMI and BMI have excellent ability to predict higher MUAC among adolescent girls. However, BMI has better ability to predict higher MUAC.

Ours is a novel study on the subject among adolescent girls. However, it is a relatively small, single centre study conducted among a particular regional ethnic girls. Our findings may not be possible to generalise to the entire population. However, we expect that our study would pave the pathway for further research on this novel field in the future.

\section{CONCLUSIONS}

The present study concluded that BMI (compared to TMI) has better association with MUAC among adolescent girls. Additionally, BMI (in comparison to TMI) has better ability to predict higher MUAC of adolescent girls. However, more studies are needed to confirm this.

\section{REFERENCES}

1. Eknoyan G, Quetelet A. The average man and indices of obesity. Nephrol Dial Transplant. 2008;23(1):47-51. DOI: $10.1093 / \mathrm{ndt} / \mathrm{gfm} 517$

2. Khosla T, Lowe CR. Indices of obesity derived from body weight and height. Br J Prev Soc Med. 1967;21(3):1228. DOI:10.1136/jech.21.3.122

3. Keys A, Fidanza F, Karvonen MJ, Kimura N, Taylor HL. Indices of relative weight and obesity. Int J Epidemiol. 2014;43(3):655-65. DOI:10.1093/ije/dyu058

4. Quetelet LAJ. A Treatise on Man and the Development of his Faculties. Edinburgh: William \& Robert Chambers; 1842 .

5. Dugdale AE. An age-independent anthropometric index of nutritional status. Am J Clin Nutr. 1971;24(2):174-6. DOI:10.1093/ajcn/24.2.174

6. Cole TJ. A critique of the NCHS weight for height standard. Hum Biol. 1985 May;57(2):183-96. PMID: 3997126.

7. Cole TJ. Weight/heightp compared to weight/height 2 for assessing adiposity in childhood: influence of age and bone age on p during puberty. Ann Hum Biol. 1986;13(5):433-51. DOI:10.1080/03014468600008621 
8. Daniels SR, Khoury PR, Morrison JA. The utility of body mass index as a measure of body fatness in children and adolescents: differences by race and gender. Paediatrics. 1997;99(6):804-7. DOI:10.1542/peds.99.6.804

9. Chrzanowska M, Koziel S, Ulijaszek SJ. Changes in BMI and the prevalence of overweight and obesity in children and adolescents in Cracow, Poland, 1971-2000. Econ Hum Biol. 2007;5(3):370-8. DOI:10.1016/j.ehb.2007.08.004

10. Telford RD, Telford RM, Welvaert M. BMI is a misleading proxy for adiposity in longitudinal studies with adolescent males: The Australian LOOK study. J Sci Med Sport. 2019 Mar;22(3):307-310. DOI: 10.1016/j.jsams. 2018.08.002.

11. Radetti G, Fanolla A, Grugni G, Lupi F, Sartorio A. Indexes of adiposity and body composition in the prediction of metabolic syndrome in obese children and adolescents: Which is the best? Nutr Metab Cardiovasc Dis. 2019 Jun 20;4753(19):30239-X. DOI: 10.1016/j.numecd.2019.06.011.

12. Das Chaudhuri AB, Basu S, Chakraborty S. Twinning rate in the Muslim population of West Bengal. Acta Genet Med Gemellol (Roma). 1993;42(1):35-9. DOI:10.1017/s0515283600042268

13. Lwanga, SK, Lemeshow S. Sample size determination in health studies: A Practical Manual. Geneva: World Health Organization, 1991.

14. Touitou Y, Portaluppi F, Smolensky MH, Rensing L. Ethical principles and standards for the conduct of human and animal biological rhythm research. Chronobiol Int. 2004;21(1):161-70. DOI:10.1081/cbi-120030045

15. Singh IP, Bhasin MK. Anthropometry, Kamla-Raj Enterprises, Delhi, 1989.

16. Perini TA, de Oliveira GL, Ornellas JS, de Oliveira FP. Technical error of measurement in anthropometry. Rev Bras Med Esporte. 2005;11(1):86-90. DOI: https://doi.org/10.1590/S1517-86922005000100009

17. Ulijaszek SJ, Kerr DA. Anthropometric measurement error and the assessment of nutritional status. Br J Nutr. 1999;82(3):165-177. DOI: https://doi.org/10.1017/S0007114599001348

18. Bulliyya G, Mallick G, Sethy GS, Kar SK. Haemoglobin status of non-school adolescent girls in three districts of Orissa, India. Int J Adolesc Med Health. 2007;19(4):395-406. DOI: https://doi.org/10.1515/IJAMH.2007.19.4.395

19. Klünder MK, Peregrina MB, Gonzalez DL, Clark P, Lora ALM. Tri-Ponderal Mass Index: A Good Anthropometric Index to Evaluate Adiposity in Children and Adolescents. ESPE Abstracts. 2018;89-133.

20. Neves FP, Alvim RO, Zaniqueli D, Pani VO, Martins CR, Peçanha MAS, et al. Tri-ponderal mass index is useful for screening children and adolescents with insulin resistance. Rev Paul Pediatr. 2020;38:e2019066. DOI: https:// doi.org/10.1590/1984-0462/2020/38/2019066

21. Khoshhali M, Heidari-Beni M, Qorbani M, Motlagh ME, Ziaodini H, Heshmat R, et al. (2020). Tri-ponderal mass index and body mass index in prediction of pediatric metabolic syndrome: the CASPIAN-V study. Arch Endocrinol Metab. 2020;64(2),171-8. DOI: https://doi.org/10.20945/2359-3997000000206

22. Shim YS. The Relationship between Tri-ponderal Mass Index and Metabolic Syndrome and Its Components in Youth Aged 10-20 Years. Sci Rep. 2019;9:14462. DOI:10.1038/s41598-019-50987-3

23. Moselakgomo VK, Van Staden M. Diagnostic accuracy of tri-ponderal mass index and body mass index in estimating overweight and obesity in South African children. Afr J Prim Health Care Fam Med. 2019;11(1):1-7. DOI: $10.4102 /$ phcfm.v11i1.1949.

24. Carrascosa A, Yeste D, Moreno-Galdó A, Gussinyé M, Ferrández Á, Clemente M, et al. Body mass index and triponderal mass index of 1,453 healthy non-obese, non-undernourished millennial children. The Barcelona longitudinal growth study. An Pediatr (Barc). 2018;89(3):137-43. DOI: 10.1016/j.anpedi.2017.12.016.

25. Jeyakumar A, Ghugre P, Gadhave S. Mid-upper-arm circumference (MUAC) as a simple measure to assess the nutritional status of adolescent girls as compared with BMI. ICAN. 2013;5(1):22-5. DOI: https://doi.org/ $10.1177 / 1941406412471848$

26. Sethi V, Gupta N, Pedgaonkar S, Saraswat A, Singh KD, Rahman HU, et al. Mid-upper arm circumference cut-offs for screening thinness and severe thinness in Indian adolescent girls aged 10-19 years in field settings. Public Health Nutr. 2019;22(12):2189-99. DOI: https://doi.org/10.1017/S1368980019000594

27. Lillie M, Lema I, Kaaya S, Steinberg D, Baumgartner JN. Nutritional status among young adolescents attending primary school in Tanzania: contributions of mid-upper arm circumference (MUAC) for adolescent assessment. BMC Public Health. 2019;19:1582. DOI:10.1186/s12889-019-7. 